\title{
Prevalence of older adults with low muscle mass living in a residential continuing care retirement community in Florida
}

\author{
Dennis Hunt ${ }^{1}$, Sareen S. Gropper ${ }^{2}$, Kelly A. Miller ${ }^{3}$, Barbara Tymczyszyn ${ }^{4}$, Deborah Chapa*5 \\ ${ }^{1}$ Rehabilitation Sciences, Florida Gulf Coast University, Fort Myers, FL, United States \\ ${ }^{2}$ Christine E. Lynn College of Nursing, Florida Atlantic University, Boca Raton, FL, United States \\ ${ }^{3}$ Jvion, Johns Creek Georgia, United States \\ ${ }^{4}$ Exercise Science Program, Florida Gulf Coast University, Fort Myers, FL, United States \\ ${ }^{5}$ Lee Memorial Health System, Fort Myers, FL, United States
}

Received: August 5, 2018

Accepted: November 15, $2018 \quad$ Online Published: November 23, 2018

DOI: $10.5430 /$ cns.v7n1p83

URL: https://doi.org/10.5430/cns.v7n1p83

\begin{abstract}
Muscle mass, strength, and function have been shown to decline with aging, and if of sufficient magnitude can result in sarcopenia. This study's objective was to determine the prevalence of low muscle mass in a group of adults living in a "premier" Florida residential continuing care retirement community. The sample consisted of 80 older adults, ranging from young old (65-74 years) to the oldest old (85+ years) with the oldest participant being 94 years. Skeletal muscle mass was assessed via bioelectrical impedance analysis. Skeletal muscle index values were calculated and compared with established cut-off values to classify each individual's muscle mass as normal or low (sarcopenic). The prevalence of sarcopenia among the males was $66 \%$ and among females was $73 \%$. When examined by age, $56 \%$ of those in their 70 s, $73 \%$ of those in their 80 s, and $79 \%$ of adults in their 90 s had low muscle mass indicative of sarcopenia. This study found a higher prevalence for sarcopenia in females and males, especially among the oldest groups, than previously reported in a nationally representative sample of adults. This study's findings also suggest the need for further studies examining whether the prevalence of low muscle mass among adults in either classification varies with socioeconomic status and ethnicity. Continuing care retirement communities may provide excellent environments for the screening, diagnosis, and implementation of exercise and nutritional programs for residents to help prevent or attenuate sarcopenia's deleterious effects. Nurse practitioners must incorporate screening for sarcopenia in their wellness package for their patients. Screening, nutritional education and support and exercise prescriptions are vital to prevent associated decline from sarcopenia.
\end{abstract}

Key Words: Sarcopenia, Exercise, Resistance exercise, Exercise prescription, Prevalence, Older adults

\section{INTRODUCTION}

Lean body mass peaks in young adulthood, between 18 and 20 years in females and 18 and 23 years in males. ${ }^{[1]}$ Losses of about $1 \%-2 \%$ of muscle mass per year begin occurring in adults at about middle-age (over 50 years), with losses as great as $30 \%$ of lean body mass observed by the time individuals reach 80 years. ${ }^{[2,3]}$ Sarcopenia has been the term used classically to refer to an age-associated progressive decline in muscle mass, although the condition is now more often defined to also include reductions in muscle strength and/or

*Correspondence: Deborah Chapa; Email: deborah.chapa@leehealth.org; Address: Lee Memorial Health System, Fort Myers, FL, United States. 
physical function (performance) ${ }^{[3,4]}$

Sarcopenia is associated with several adverse outcomes including decreased independence, early onset disability, and functional limitations. Increased risks of frailty, falls, and fractures have also been documented in individuals with sarcopenia. ${ }^{[5-10]}$ Increased risks of postoperative complications, as well as increased length of stay and likelihood of re-hospitalization are also found among hospitalized patients with sarcopenia. ${ }^{[11-13]}$ Moreover, in individuals with co-morbid conditions, including cancer and heart, renal, and respiratory diseases, reduced muscle mass is associated with increased mortality. ${ }^{[14-19]}$

The relatively new (as of October 2016) ICD-10-CM code M62.84 provides the opportunity for practitioners to diagnose sarcopenia in patients. ${ }^{[20]}$ Yet, a lack of consensus among various study/working groups, including, for example, the European Working Group on Sarcopenia in Older People, ${ }^{[21]}$ the International Working Group on Sarcopenia, ${ }^{[3,22]}$ and the Foundation for the National Institutes of Health Sarcopenia Project, ${ }^{[4]}$ regarding the definition and diagnosis of sarcopenia remains problematic. The disharmony is associated primarily with the varying approaches used to determine the adequacy of the absolute muscle mass that is present. ${ }^{[23,24]}$ Moreover, the multitude of approaches has led to wide disparities in the reported prevalence of sarcopenia, which, for example, range from about $7 \%$ to over $59 \%$ in communitydwelling older adults living in the United States, although higher percentages in individuals in long-term and acute care settings have been evidenced. ${ }^{[9,22,25-27]}$ The new ICD-10CM code permits all medical providers reimbursement for diagnosing sarcopenia. This is critical as now nurse practitioners can assess for this important disease process early to hopefully provide interventions that will combat this disease process.

\section{Objective}

The objective of this study was to determine the prevalence of low muscle mass (i.e. sarcopenia) among a group of older adults living in a Florida residential continuing care retirement community.

\section{METHODS AND DATA COLLECTION}

Adults over the age of 50 years were recruited from a retirement community with 384 residences located on 83 acres in South Florida. The community, which is marketed as a "premier" continuing care retirement community (CCRC), is home to more than 700 residents, who live in one of four environments: independent living, assisted living, skilled nursing, and at-home living. Recruitment for the study occurred by advertisements on the community's in-house television network and by flyers sent to residents in the independent living community. The project was explained to prospective participants, and informed consent was acquired from those interested in participation. Exclusions to project participation included individuals having any orthopedic or cardiovascular implants.

Demographic information, including gender, age, and ethnicity, was collected from participants. Height was measured using a vertical measuring tape, and weight was measured using an electronic scale (Health-O-Meter, Model 349KLX). Body mass index (BMI) was calculated for each participant as weight $(\mathrm{kg}) /$ height $^{2}(\mathrm{~m})$. Participants were classified as underweight, normal, overweight, or obese according to Centers for Disease Control and Prevention definitions. ${ }^{[28]}$

Body composition was assessed via bioelectrical impedance analysis (RJL Systems BIA-Quantum IV Analyzer ${ }^{\mathrm{R}}$ ). First, participants were asked to lie down in a supine position on a portable physical therapy table. Once positioned on the table, electrodes were placed on their right hand and right foot to obtain both resistance and reactance values. Whole-body (total) skeletal muscle mass was calculated using the average resistance values (ohms) from three sequential BIA assessments and using the prediction equation of Janssen et al. ${ }^{\text {[9] }}$ This equation was developed and cross-validated against magnetic resonance imaging measures of whole-body muscle mass in a sample of 269 men and women ranging in age from 18 to 86 years and in BMI from 16 to $48 \mathrm{~kg} / \mathrm{m}^{2}{ }^{[9,29]}$

Skeletal muscle index (SMI) was calculated for each participant by dividing skeletal muscle mass $(\mathrm{kg})$ by body weight (kg) and multiplying by 100; SMI adjusts for stature and non-skeletal muscle tissues (fat, organ, and bone mass). ${ }^{[9]}$ Each participant's SMI value was then classified as normal or sarcopenic, either class I or II, based on cut-off values established from the Third National Health and Nutrition Examination Survey (NHANES III) data. ${ }^{[9]}$ An SMI was considered normal if it was greater than one standard deviation above the sex-specific mean for over 6,000 young adults (aged 18 to 39 years) from the NHANES III data. Class I sarcopenia was deemed present if the SMI was within one to two standard deviations, and class II sarcopenia was diagnosed if the SMI was below two standard deviations of young adult values. ${ }^{[9]}$

\section{Results}

Study participants included 80 older adults ( 32 males and 48 females) with an average age of $83.40( \pm 5.30)$ years (males $83.97 \pm 5.31$, and females $83.02 \pm 5.31$ ). The participants' ages ranged from 70 to 94 years, with 18 participants in their $70 \mathrm{~s}, 48$ participants in their $80 \mathrm{~s}$, and 14 participants in their 
90s. The majority of the participants were Caucasian.

The BMI of the males and females averaged 26.0 and 24.2 $\mathrm{kg} / \mathrm{m}^{2}$, respectively. Based on BMI, the majority, $56 \%$, of the males had a BMI in the overweight category, $38 \%$ were categorized as normal, and $6 \%$ were obese (see Table 1). Of the females, the majority, 67\%, had a BMI in the normal category, $27 \%$ were overweight, $4 \%$ were obese, and $2 \%$ were underweight (see Table 1).
The prevalence of sarcopenia based on low muscle mass among the males and females was $66 \%$ and $73 \%$, respectively (see Table 1). The overwhelming majority had class I sarcopenia, specifically $59 \%$ of the males and $65 \%$ of the females. Only $6 \%$ of males and $8 \%$ of females had class II sarcopenia. An examination of the prevalence of sarcopenia based on low muscle mass by age found that $56 \%$ of adults in their 70 s had sarcopenia, $73 \%$ of those in their $80 \mathrm{~s} \mathrm{had}$ sarcopenia, and $79 \%$ of adults in their 90 s had sarcopenia.

Table 1. Skeletal mass index by BMI of a group of older adults living in a continuing care residential community in Florida

\begin{tabular}{|c|c|c|c|c|c|c|c|c|}
\hline & \multicolumn{8}{|c|}{ Skeletal Mass Index } \\
\hline & \multicolumn{4}{|c|}{ Males } & \multicolumn{4}{|c|}{ Females } \\
\hline & $\mathbf{n}$ & $\begin{array}{l}\text { Normal } \\
>37 \%\end{array}$ & $\begin{array}{c}\text { Class I } \\
\mathbf{3 1 \%}-\mathbf{3 7 \%}\end{array}$ & $\begin{array}{c}\text { Class II } \\
<31 \%\end{array}$ & $\mathbf{n}$ & $\begin{array}{c}\text { Normal } \\
>\mathbf{2 8 \%}\end{array}$ & $\begin{array}{c}\text { Class I } \\
22 \%-28 \%\end{array}$ & $\begin{array}{c}\text { Class II } \\
<22 \%\end{array}$ \\
\hline Overall & 32 & 11 & 19 & 2 & 48 & 13 & 31 & 4 \\
\hline \multicolumn{9}{|l|}{ BMI $\left(\mathrm{kg} / \mathrm{m}^{2}\right)$} \\
\hline - Underweight & 0 & - & - & - & 1 & 1 & - & - \\
\hline - Normal & 12 & 7 & 4 & 1 & 32 & 12 & 19 & 1 \\
\hline - Overweight & 18 & 4 & 13 & 1 & 13 & - & 11 & 2 \\
\hline - Obese & 2 & - & 2 & - & 2 & - & 1 & 1 \\
\hline
\end{tabular}

\section{DiscusSION}

The presence of sarcopenia among this group of older adults living in a "premier" residential continuing care retirement community in Florida was higher in both females at $73 \%$ (65\% class I and $8 \%$ class II) and among males, 66\% (59\% class I and 7\% class II) than found in previous investigations. These findings are potentially noteworthy especially for the males. Conclusions reached from the 4,504 adults aged 60 and older (average age $70 \pm 7$ years) from the NHANES III data reported $69 \%$ of the females (59\% class I and $10 \%$ class II) and just $51 \%$ of the males ( $45 \%$ class I and $6 \%$ class II) were considered sarcopenic. ${ }^{[9]}$ The study by Janssen et al. ${ }^{[9]}$ provides an estimation of the prevalence of sarcopenia among a large, ethnically diverse group of older adults, including 2,298 women and 2,224 men aged 60 years and older, in the United States. The higher overall prevalence in the present study may be age-related with a 10-year older mean age of participants in the present study versus the NHANES sample. Muscle mass loss increases with age, ${ }^{[30]}$ although prevalence data on class I and II sarcopenia has been shown in earlier studies to remain constant among adults after the sixth decade. ${ }^{[9,23]}$

Additionally, this study's population, being primarily Caucasians, was not as ethnically and socioeconomically diverse as the NHANES III sample. Whether the prevalence of sarcopenia varies with ethnicity, it is difficult to ascertain from the published scientific literature possibly due to the

Published by Sciedu Press multiple approaches used for its diagnosis. An examination of ethnicity-related differences in skeletal muscle, however, showed the greatest declines with aging in the muscle mass of females occurring in African Americans, followed by Asians, Whites, and Hispanics. ${ }^{[31]}$ Among males, Hispanics exhibited the greatest decline in muscle mass per decade followed by African Americans and Whites. ${ }^{[31]}$ Earlier findings based on muscle mass suggest Caucasians may be at lower risk for muscle mass losses compared with other ethnic groups although this fact is not supported by the current study's findings.

This study's population also likely had a relatively high socioeconomic status based on their residence in a marketed "premier" CCRC in South Florida. In the United States, there are over 2,000 CCRCs, with entrance fees ranging from $\$ 100,000$ to $\$ 1$ million, and monthly fees averaging about $\$ 3,000$. ${ }^{[32]}$ Thus, while questions about income were not directly asked of the study participants, CCRC residents were thought to have fairly high socioeconomic means, especially in this "premier" facility. Studies examining the prevalence of sarcopenia based on socioeconomic status were not found in a review of the scientific literature. While BMI typically declines with aging, ${ }^{[33]}$ studies also have found that women of higher socioeconomic status tend to be thinner than those from lower socioeconomic status. ${ }^{[34,35]}$ It is also possible that while participants in this study were in the independent living section of the CCRC, they may have selected to re- 
side in a CCRC because they were at "higher risk"; a factor which could contribute the higher prevalence. Higher levels of dieting have also been found among women with higher incomes. ${ }^{[34-36]}$ The prevalence of disordered eating among women, over 50 and 60 years of age, is increasing, with past diagnosis and stressors such as divorce or relationship problems, "empty-nest" syndrome, death of a parent, fears from aging, and desire to look younger, among others, associated with its onset in this age group. ${ }^{[37]}$ Poor dietary intake, especially without attention to energy and protein intakes, and insufficient physical activity, especially strength training exercises, can accelerate the loss of muscle mass and contribute to the development of sarcopenia and sarcopenic obesity. Low muscle mass was found in the present study among men and women with low (underweight), normal, as well as high BMIs (overweight and obese). Similar findings have been reported in other studies. ${ }^{[38]}$ Studies are needed examining whether the prevalence of low muscle mass varies among individuals based on socioeconomic status. Such studies should also evaluate key lifestyle habits including diet and exercise. With increased focus on lifestyle medicine for prevention and treatment of chronic disease, these facts are key for nurses and nurse practitioners providing wellness education and support. Sarcopenia is present in all populations and all patients must be screened.

\section{Conclusions}

This study's findings indicate a high prevalence of sarcopenia in both males and females. Although somewhat consistent with those from a larger nationally representative sample of older adults living in the United States, this study illustrates that socioeconomic status may not be an independent predictor of sarcopenia. Additionally, a major consideration from this study and others is that it continues to be documented that the loss of muscle mass occurs in the majority of older adults. More studies are needed to examine whether or not the prevalence of sarcopenia varies significantly based on ethnicity or socioeconomic status. Research also should evaluate best screening modalities for the patient in their primary care setting. This would also include the pathways for prevention and treatment that would include dietary and exercise prescriptions from licensed dietitians and exercise physiologists. Nurses and nurse practitioners are vital to the process of screening, education and referrals to other trained professionals on the interdisciplinary team for patients to prevent and improve health. Given its adverse effects, it is recommended that all older adults be screened for sarcopenia. Moreover, CCRCs represent excellent environments for the implementation of exercise and nutritional education programs for its residents to help prevent and treat sarcopenia.

\section{CONFLICTS OF INTEREST DisClosure}

The authors declare they have no conflicts of interest.

\section{REFERENCES}

[1] Boot AM, de Ridder MAJ, van der Sluis IM, et al. Peak bone mineral density, lean body mass and fractures. Bone. 2010; 46: 336341. PMid: 19833245. https://doi.org/10.1016/j.bone.2 009.10 .003

[2] Koopman R, van Loon LJC. Aging, exercise and muscle protein metabolism. Journal of Applied Physiology. 2009; 106: 2040-2048. PMid: 19131471. https://doi.org/10.1152/japplphysiol .91551 .2008

[3] Fielding RA, Vellas B, Evans WJ, et al. Sarcopenia: an undiagnosed condition in older adults. Current consensus definition: prevalence, etiology, and consequences. International working group on sarcopenia. Journal of the American Medical Directors Association. 2011; 12(4): 249-256. PMid: 21527165. https://doi.org/10.1016/j jamda.2011.01.003

[4] Studenski SA, Peters KW, Alley DE, et al. The FNIH sarcopenia project: rationale, study description, conference recommendations, and final estimates. Journals of Gerontology. Series A, Biological Sciences and Medical Sciences. 2014; 69(5): 547-558. PMid: 24737557. https://doi.org/10.1093/gerona/glu010

[5] Balogun S, Winzenberg T, Wills K, et al. Prospective associations of low muscle mass and function with 10-year falls risk, incident fracture and mortality in community dwelling older adults. Journal of
Nutrition, Health and Aging. 2017; 21(7): 843-848. PMid: 28717816. https://doi.org/10.1007/s12603-016-0843-6

[6] Castillo EM, Goodman-Gruen D, Kritz-Silverstein D, et al. Sarcopenia in elderly men and women: The Rancho Bernardo study. American Journal of Preventive Medicine. 2003; 25(3): 226-231. https://doi.org/10.1016/S0749-3797 (03)00197-1

[7] Cesari M, Leeuwenburgh C, Lauretani F, et al. Frailty syndrome and skeletal muscle: results from the Invecchiare in Chianti study. American Journal of Clinical Nutrition. 2006; 83(5): 1142-1148. PMid: 16685058. https://doi.org/10.1093/ajcn/83.5.1142

[8] Hairi NN, Cumming RG, Naganathan V, et al. Loss of muscle strength, mass (sarcopenia), and quality (specific force) and its relationship with functional limitation and physical disability: The Concord Health and Ageing in Men Project. Journal of the American Geriatrics Society. 2010; 58(11): 2055-2062. https://doi.org/ $10.1111 / \mathrm{j} .1532-5415.2010 .03145 . \mathrm{x}$

[9] Janssen I, Heymsfield SB, Ross R. Low relative skeletal muscle mass (sarcopenia) in older persons is associated with functional impairment and physical disability. Journal of the American Geriatrics Society. 2002; 50(5): 889-896. PMid: 12028177. https: //doi.org/10.1046/j.1532-5415.2002.50216.x

[10] Zoltick ES, Sahni S, McLean RR, et al. Dietary protein intake and subsequent falls in older men and women: the Framingham 
Study. Journal of Nutrition, Health \& Aging. 2011; 15(2): 147-152. https://doi.org/10.1007/s12603-011-0028-2

[11] Bohannon RW, Maljanian R, Ferullo J. Mortality and readmission of the elderly one year after hospitalization for pneumonia. Aging Clinical and Experimental Research. 2004; 16(1): 22-25. PMid: 15132287. https://doi.org/10.1007/BF03324527

[12] Fiatarone-Singh M, Singh N, Hansen R, et al. Methodology and baseline characteristics for the sarcopenia and hip fracture study: a 5-year prospective study. Journals of Gerontology Series A: Biological Sciences \& Medical Sciences. 2009; 64A(5): 568-574. PMid: 19228788. https://doi.org/10.1093/gerona/glp002

[13] Gariballa S, Alessa A. Sarcopenia: prevalence and prognostic significance in hospitalized patients. Clinical Nutrition. 2013; 32(5): 772-776. PMid: 23395102. https://doi.org/10.1016/j.clnu .2013 .01 .010

[14] Ali R, Baracos VE, Sawyer MB, et al. Lean body mass as an independent determinant of dose-limiting toxicity and neuropathy in patients with colon cancer treated with FOLFOX regimens. Cancer Medicine. 2016; 5(4): 607-616. PMid: 26814378. https: //doi.org/10.1002/cam4.621

[15] Arrieta O, De la Torre-Vallejo M, López-Macías D, et al. Nutritional status, body surface, and low lean body mass/body mass index are related to dose reduction and severe gastrointestinal toxicity induced by afatinib in patients with non-small cell lung cancer. The Oncologist. 2015; 20(8): 967-974. PMid: 26173839. https://doi.org/10.1634/theoncologist.2015-0058

[16] Harada K, Suzuki S, Ishii H, et al. Impact of skeletal muscle mass on long-term adverse cardiovascular outcomes in patients with chronic kidney disease. American Journal of Cardiology. 2017; 119(8): 12751280. PMid: 28215411. https://doi.org/10.1016/j.amjcar d. 2017.01 .003

[17] Hirai K, Ookawara S, Morishita Y. Sarcopenia and physical inactivity in patients with chronic kidney disease. Nephrourology Monthly. 2016; 8(3): e37443. PMid: 27570755. https://doi.org/10.581 $2 /$ numonthly. 37443

[18] dos Santos MR, Saitoh M, Ebner N, et al. Sarcopenia and endothelial function in patients with chronic heart failure: Results from the Studies Investigating Comorbidities Aggravating Heart Failure (SICA-HF). Journal of the American Medical Directors Association. 2017; 18(3): 240-245. PMid: 27816483. https://doi.org/10.1 016/j.jamda. 2016.09.006

[19] Lavie CJ, De Schutter A, Patel DA, et al. Body composition and survival in stable coronary heart disease: impact of lean mass index and body fat in the "obesity paradox". Journal of the American College of Cardiology. 2012; 60(15): 1374-1380. PMid: 22958953. https://doi.org/10.1016/j.jacc. 2012.05.037

[20] Anker SD, Morley JE, Haehling S. Welcome to the ICD-10 code for sarcopenia. Journal of Cachexia, Sarcopenia and Muscle. 2016; 7(5): 512-514. PMid: 27891296. https://doi.org/10.1002/jcsm. 1 2147

[21] Cruz-Jentoft AJ, Baeyens JP, Bauer JM, et al. Sarcopenia: European consensus on definition and diagnosis Report of the European Working Group on Sarcopenia in Older People. Age and Ageing. 2010; 39(4): 412-423. PMid: 20392703. https://doi.org/10.1093/ ageing/afq034

[22] Cruz-Jentoft AJ, Landi F, Schneider SM, et al. Prevalence of and interventions for sarcopenia in ageing adults a systematic review. Report of the International Sarcopenia Initiative (EWGSOP and IWGS). Age and Ageing. 2014; 43(6): 748-759. http://dx.doi.org/10. 1093/ageing/afu115

[23] Kim KM, Jang HC, Lim S. Differences among skeletal muscle mass indices derived from height-, weight- and body mass index-adjusted models in assessing sarcopenia. Korean Journal of Internal Medicine. 2016; 6: 643-650. PMid: 27334763. https ://doi.org/10.3904/ $\mathrm{kjim} .2016 .015$

[24] Masanes F, Rojanoiluque X, Salva A, et al. Cut-off points for muscle mass - not grip strength or gait speed - determine variations in sarcopenia prevalence. Journal of Nutrition, Health and Aging. 2017; 21(7): 825-829. https://doi.org/10.1007/s12603-016-084 4-5

[25] Lourenco RA, Perez-Zepeda M, Gutierrez-Robledo L, et al. Performance of the European Working Group on Sarcopenia in older people algorithm in screening older adults for muscle mass assessment. Age and Aging. 2015; 44: 334-338. PMid: 25539836. https://doi.org/10.1093/ageing/afu192

[26] Morley JE, Anker SD, von Haehling S. Prevalence, incidence, and clinical impact of sarcopenia: facts, numbers, and epidemiologyupdate 2014. Journal of Cachexia, Sarcopenia and Muscle. 2014; 5(4): 253-259. PMid: 25425503. https ://doi .org/10.1007/s1 3539-014-0161-y

[27] Muller MJ, Geisler C, Pourhassan M, et al. Assessment and definition of lean body mass deficiency in the elderly. European Journal of Clinical Nutrition. 2014; 68: 1220-1227. PMid: 25139559. https://doi.org/10.1038/ejcn. 2014.169

[28] Centers for Disease Control and Prevention. 2016. Defining Adult Overweight and Obesity. Accessed November 28, 2017. Available from: https://www.cdc.gov/obesity/adult/defining.htm 1

[29] Janssen I, Heymsfield SB, Wang ZM, et al. Skeletal muscle mass and distribution in 468 men and women aged 18-88 years. Journal of Applied Physiology. 2000; 89: 81-88. PMid: 10904038. https://doi.org/10.1152/jappl.2000.89.1.81

[30] Mitchell WK, Williams J, Atherton P, et al. Sarcopenia, dynapenia and the impact of advancing age on human skeletal muscle size and strength; a quantitative review. Frontiers in Physiology. 2012; 3: 118. PMid: 22934016. https://doi.org/10.3389/fphys . 2012 .00260

[31] Silva AM, Shen W, Heo M, et al. Ethnicity-related skeletal muscle differences across the lifespan. American Journal of Human Biology. 2010; 22(1): 76-82. PMid: 19533617. https://doi.org/10.100 2/ajhb. 20956

[32] Assisted Living Federation of America. The costs of a Continuing Care Retirement Community. Accessed October 11, 2017. Available from: https://www. caring.com/articles/costs-of-a - continuing-care-retirement-community

[33] Centers for Disease Control and Prevention. Adult Obesity Prevalence Maps. 2016a. Accessed November 28, 2017. Available from: https://www.cdc.gov/obesity/data/prevalence-m aps.html

[34] Jeffrey RW, French SA. Socioeconomic status and weight control practices among 20- to 45-year-old women. American Journal of Public Health. 1996; 86(7): 1005-1010. https://doi.org/10.2 105/AJPH. 86.7.1005

[35] Lin BH, Huang CL, French SA. Factors associated with women's and children's body mass indices by income status. International Journal of Obesity. 2004; 28: 536-542. PMid: 14770199. https: //doi.org/10.1038/sj.ijo.0802604

[36] Nevonen L, Norring C. Socio-economic variables and eating disorders: A comparison between patients and normal controls. Eating and Weight Disorders. 2004; 9(4): 279-284. PMid: 15844400. https://doi.org/10.1007/BF03325082

[37] Gagne DA, Holle AV, Brownley KA, et al. Eating disorder symptoms and weight and shape concerns in a large web-based convenience sample women ages 50 and above: Results of the gen- 
der and body image (GABI) study. International Journal of Eating Disorders. 2012; 45(7): 832-844. PMid: 22729743. https: //doi.org/10.1002/eat.22030
[38] Graf CE, Pichard C, Herrmann FR, et al. Prevalence of low muscle mass according to body mass index in older adults. Nutrition. 2017; 34: 124-129. PMid: 28063507. https://doi.org/10.1016/j . nut.2016.10.002 